\title{
6
}

\section{Imaginative Leadership: A Conceptual Frame for the Design and Facilitation of Creative Methods and Generative Engagement}

Kelli R. Pearson

\section{Introduction}

At the very least, participatory involvement with the many forms of art can enable us to see more in our experience, to hear more on normally unheard frequencies, to become conscious of what daily routines have obscured, what habit and convention have suppressed-Maxine Greene (1995: 123)

Complex sustainability challenges can only be understood and addressed via ambiguous subjective judgements, which are shaped by the inner dimensions of individuals and groups, such as their worldviews, imaginaries, interests/motivations, values, and ideologies (Rittel \& Webber, 1973). Effective change processes must therefore include

K. R. Pearson $(\varangle)$

Department of Education and Learning Science, Wageningen University, Wageningen, The Netherlands 
cultural transformations and move beyond an exclusive focus on datadriven, technical, policy-oriented, and biophysical solutions (Boyden, 2001). However, even taking the inner-dimensions into account, actuating change is often constrained by the power and inertia of entrenched ways of thinking and perceiving, habituated everyday practices, and social/contextual norms and conventions (Ajzen, 1991; Dewey, 1922; Greene, 1995; Kagan, 2011). Moreover, the human psyche is hardwired to disengage when faced with information that appears overwhelmingly difficult or disturbing and can result in apathy and eco-anxiety (Lertzman, 2015; Pihkala, 2020).

With the aspiration to support transformative change and disrupt habits of thinking and doing, many scholars argue for a 'humanistic' (Hulme, 2011) or 'artistic' (Kagan, 2017) turn in sustainability transformations. ${ }^{1}$ A humanistic turn calls for drawing from the arts and humanities and from the fields of psychology, cognitive sciences, theology, philosophy, and cultural studies. In fact, the arts have played a vital role in social transformations throughout history (see Belfiore \& Bennett, 2008), and many studies point to the potential role of arts and culture in supporting sustainability transformations specifically (Hawkins et al., 2015; Kagan, 2011; Kepes, 1972; Rathwell, 2016).

Research suggests that arts-based and creative practices are well-suited for engaging with the inner dimensions of sustainability (Horlings, 2017). One such approach can be termed 'generative engagements' (Eernstman et al., 2021); these include experiences or events that evoke multiple forms of intelligence (Gardner, 2011) and enable emotional, aesthetic, cognitive, somatic, and social processing (Eisner, 2002; Gardner, 2011). The process of physically creating 'practicalaesthetic' artefacts, for example, enables a process of 'thinking with our hands' (Groth, 2017; Sheridan et al., 2014) and gives us multimodal experiences that support meaning-making processes, individually and as

\footnotetext{
1 'Sustainability transformations' is understandably a flexible and fuzzy term as it frequently makes its way back and forth between various academic disciplines and the world of practice and policy. At its core, however, it is a way to distinguish transformative change (i.e., change that alters the fundamental properties of a system) from transitional change (processes that emphasize incremental change). For a systematic literature review of sustainability transformations, see Salomaa and Juhola (2020).
} 
social and cultural beings (Gulliksen, 2017). Generative engagements can facilitate and trigger the exchange and co-creation of knowledge through making and sharing artefacts (Groth, 2017), by spanning and connecting knowledge systems (Rathwell et al., 2015), through embodied learning and knowing (Gulliksen, 2017), and through playful experimentation (Nørgård et al., 2017). They can also support people to reflect on their deepest values, ethics, and motivations-what they care about and why it is worth taking action (Eernstman \& Wals, 2013). While addressing heavy, potentially overwhelming topics, generative engagements also include the motivating and vitalizing affective elements of pleasure (Hammond et al., 2018), humour and light-heartedness (Eernstman et al., 2021), and joy (see Morrigi, this volume).

Generative engagements focused on sustainability can take many forms including, for example, collective artist residencies (Eernstman et al., 2021), immersive/interactive art installations or performances (see Weintraub, 2012), or learning environments and workshops that make use of creative methods (Galafassi, 2018; Taylor \& Ladkin, 2009). Creative practices are also widely used in research processes, particularly in participatory action research (PAR) and transdisciplinary research (TDR) (Kagan, 2011; Wang et al., 2017). Still, there is a gap in understanding how creative methods can be designed specifically to evoke and support mindsets that are conducive to sustainability transformations.

Therefore, in the spirit of generative, playful, and 'exuberant' experimentation (Hollings, 2004), this chapter addresses the question: How can creative methods be operationalized (via generative engagements) to support the imaginative leadership capacities of researchers and practitioners working in the arena of sustainability? ${ }^{2}$ I use the term imaginative leadership (see below) to describe the ability to understand and consciously influence the symbolic/metaphorical dimensions of self and others that are linked to specific values, mindsets, worldviews.

In addressing the above question, this chapter reflects on the process of co-designing and facilitating two different workshops grounded in

\footnotetext{
2 Although they can generally be used interchangeably, this chapter uses the more inclusive term creative methods instead of arts-based methods. Is the process of cooking together, for example, an arts-based method? That is debatable, but if used in the context of a workshop or residency, it could certainly be considered a creative method of participatory engagement.
} 
creative practices and methods. It proposes a conceptual frame that links creative methods to specific transformative mindsets. Both workshops aimed to support the imaginative leadership of sustainability researchers and practitioners by (a) activating specific conceptual frames and processes of self-reflection with the potential to open new spaces of possibility for sensing, perceiving, feeling, and acting, and (b) inviting participants to disrupt default anthropocentric worldviews and timescales and to draw more deeply and consciously from their own values and motivations in their work as sustainability professionals or researchers. ${ }^{3}$ This chapter focuses primarily on the process of designing the methods and workshops - the theoretical inputs and practicalities that shaped them-rather than on the methods themselves (for a detailed description of all the specific methods used during workshops, see Pearson et al., 2018 or Pearson n.d.).

First, this chapter gives an overview of the workshops and the methodology of the research process. Second, it introduces the key sensitizing concepts of transformative imagination and imaginative leadership, and third, it presents a preliminary list of transformative mindsets that emerged from literature, semi-structured interviews, and the codesign process. Fourth, it describes the design and implementation of the workshops, including limitations. Fifth, emerging from the co-reflection process, it proposes an updated set of transformative mindsets for use in developing a framework for imaginative leadership moving forward, and then ends with concluding thoughts.

\footnotetext{
${ }^{3}$ I follow the school of thought that centres the role of physical, institutional, social, and cultural structures and systems in perpetuating unsustainability, as opposed to focusing on a pro-sustainability behaviour change of individuals (e.g., reducing carbon footprint or making sustainable consumption choices).
} 


\section{Developing Creative Methods Workshops to Support Imaginative Leadership: An Overview of the Research Process}

The only way to approach such a period in which uncertainty is high and one cannot predict what the future holds, is not to predict, but to experiment and act inventively and exuberantly via diverse adventures in living-C. S. Holling (2004: 8)

The workshops described in this chapter enabled collaborative development and experimentation with unconventional methods for sustainability leadership within the conventional form of a workshop. The aim was to support the agency and self-efficacy of key individuals/systems entrepreneurs already working towards sustainability transformations, as a leverage point for systemic and cultural change.

First, the Action Hub: Arts-based methods for transformative design (referred to henceforth as 'Action Hub') was a 90-min practice session with approximately 30 participants conducted during Transformations 2017, a transdisciplinary conference that took place in Dundee, Scotland. Co-designers included a cohort of six researchers from the SUSPLACE Innovation Training Network. ${ }^{4}$ The co-designers chose this conference as the arena for our experimentation as it is known for encouraging non-traditional conference contributions, it includes both academics and practitioners, and it is supportive of creative and experiential methods for sustainability transformations.

Second, Imaginative Leadership: Co-producing with nature and communities (referred to henceforth as 'Imaginative Leadership') was a full day workshop for sustainability professionals in the Welsh Government working in the area of community engagement. The concept was initiated together with a representative of the Welsh government specializing in leadership and sustainability. Additional co-designers

\footnotetext{
${ }^{4}$ SUSPLACE was an EU Horizon 2020 funded Marie Skłodowska-Curie Actions Innovation Training Network (2015-2019) focused on understanding 'sustainable-place shaping' from multiple perspectives.
} 
included a professional performance artist working at the intersection of art and sustainability and transformative practices and a social entrepreneur working with Natural Resources Wales. The artist was hired as the primary facilitator of the events and the other two co-designers participated as participant-observers. The same workshop structure was repeated with two different groups of approximately 40 people each (one in northern and one in southern Wales) on two separate days.

The focus of these experiments was not to track the impact of specific methods, but to use the design and implementation process as an arena for reflection, for reality testing the use of creative methods in the process of developing a theoretical framework for designing and applying creative methods, and to probe promising pathways for future practice and research. The learning process can be broken into four (non-linear) phases that incorporated iterative loops throughout: (1) exploration, (2) collaborative workshop design, (3) execution, (4) reflection.

\section{Phase 1: Exploration}

The exploration phase combined semi-structured expert interviews with a wide, cross-disciplinary sampling of literature related to the inner dimensions of sustainability transformations. In total, I conducted 14 semi-structured interviews in the Netherlands and the UK with people who work at the intersection of arts-based or creative practices in facilitation, community engagement, and sustainability (identified via snowballing). They were intended to give insight into how and why professional practitioners use creative methods, as well as what makes them successful and/or challenging (in their perspective). Literature guided the direction of interview questions, and the interviews, in turn, pointed to additional arenas of relevant academic research and theory.

Early influences that shaped my conceptualization of creative practices for sustainability transformations included academic literature in the arenas of art and aesthetic experience (e.g., Dewey, 1934), artbased environmental education (Mantere, 1998; van Boeckel, 2013), and multiple intelligences theory (Gardner, 2011). Together these strains of literature emphasize the role of art for sense-making, engaging diverse 
styles of learning and knowing, processing information through multiple senses and somatic-cognitive processes, re-sensitizing ourselves to the environment (and specific places), releasing conditioned perceptions, and engaging with sustainability issues (and each other) based on depth of emotional experience. From a practice perspective, I was influenced by my experience with Joanna Macy's Work the Reconnects (Macy \& Brown, 2014) and the social and earth-based practices found in permaculture (Macnamara, 2012). Both experiment with new, transformative ways of relating to the natural world, and both incorporate creative and pragmatic practices that highlight attentiveness to emotions, to interdependencies, to inter-relationships between people, and to the details, rhythms, and cycles of natural systems. Finally, the methodological frameworks of Appreciative Inquiry (AI) (Cooperrider \& Whitney, 2001) and Participatory Action Research (PAR) influenced my overall approach. AI shifts attention from 'solving' problems, to strengthening what is already working, including re-appreciating more intangible placebased resources (i.e., Horlings et al., 2020) and can be linked to designing creative methods for sustainability transformations (covered more thoroughly in Moriggi, this book). PAR acknowledges and highlights the dual role of the researcher as a scientist and social change agent, particularly in light of the need for urgent sustainability transformations (Wittmayer \& Schäpke, 2014; see also De La Rosa, this volume).

\section{Phase 2: Collaborative Workshop Design}

The concept of the workshop format was first described by Osborn in Applied Imagination (1953) in which he outlined methods for creative group problem-solving. From their inception, workshops were intended to spark imagination and collective creativity (Isaksen et al., 2010). Workshops were chosen as the arena for experimentation in part because the format is highly accessible to a range of participants, it requires a relatively low-time commitment on the part of participants, and it is a familiar, 'safe' structure, which is important when people are working outside of their comfort zones (Sol et al., 2013). 
Each workshop was co-designed with a different constellation of collaborators (co-researchers, stakeholders, and practitioners). Co-design is understood here as a joint team effort to initiate, develop and implement a participatory process. Although the workshops were different in terms of collaborators, size, participant profiles, content, and length, there were elements common to both. First, they were targeted towards people who already work in sustainability-related arenas and therefore the intent was not to change participants' minds or even to persuade or influence them, but instead help them access mindsets that they already value. Second, in order to set the stage for productive collaboration, each experiment began with a series of discussions around workshop goals and parameters, including personal goals, research goals, motivational goals (e.g., planetary health or 'islands of sanity') and participant-centred goals (i.e., what would be most useful and generative from the perspective of targeted participants?). In each case, the final step was to design the overall workshop concept and the specific methods. Data collected from this phase consisted of meeting notes, workshop design drafts (that included goals for each activity), and detailed final agendas, together with guidelines for spoken scripts, room set-up, and materials. Still, the nature of collaboration is often ad hoc and messy, and the chaotic demands of practice often subsume tidy categories and intentionality of theory.

\section{Phase 3: Execution}

The execution phase included the actual set-up, production, and facilitation of each event. Data collected included various documents, and artefacts were produced including presentations and notes, written instructions for participants, photographs, short video clips in some cases, and creative outputs/artefacts resulting from specific methods (collages, poems, etc.).

\footnotetext{
${ }^{5}$ Margaret Wheatley (2017) proposes that whether or not humans can stem the tide towards unsustainability, we have the possibility to contribute to 'islands of sanity' that evoke the "conditions for our basic human qualities of generosity, contribution, community and love" (p. 8).
} 


\section{Phase 4: Reflection}

To reflect on the design process and resulting workshops, I drew from both practice-led research and art-based and qualitative methods. Practice-led research is widely used in the context of creative arts and performance studies. It employs iterative cycles of doing/creating and reflection (Candy, 2006) that contribute either to a body of theory or to a more pragmatic concept of social usefulness (Smith, 2009) or new knowledge gained (Mäkelä, 2007). The practitioner-researcher assesses the value and potential of a practical engagement in the world (i.e., the making of an object or a creative process) through reflection and evaluation. In this case, the 'practice' consisted of the creative development and implementation of the workshops. Reflection consisted of discussion sessions with co-collaborators and participant-observers, and was also informed by end-of-session evaluations and follow-up questionnaires. It also involved extended periods of interaction with co-designers engaged in what Clifford Geertz (1998) terms 'deep hanging out'-spending formal and informal time together reviewing and revisiting insights and learnings again and again.

AI also influenced the reflection process by focusing attention on what worked and what contributed to the successes and areas of vitality in the process of designing and executing the workshops (not, of course, to the exclusion of critical discernment - see Morrigi, this book). Finally, reflection was supported by the process of synthesizing findings from both workshops into a toolkit and open-source database (reimginary.com) for researchers and practitioners, which describes each specific method and our overall approach in great detail (see Pearson et al., 2018; Pearson, n.d). 


\section{Sensitizing Concepts: Imaginative Leadership and Transformative Mindsets}

Ideas are as important as facts and nowhere is it evident that they are inducable from them. We need imagination not rules; intuition not technique; warm ideas not cold facts; inventive people not conformists, fertile thinking not rigid rules to follow-Arthur P. Bochner (2009: 363)

In 1954, Herbert Blumer argued for the value of 'sensitizing concepts' in social sciences research. In contrast to 'definitive concepts', sensitizing concepts "merely suggest directions along which to look...they rest on a general sense of what is relevant" (p. 7). In accordance with Blumer, this research was guided by the concept of the transformative imagination (Galafassi, 2018); this assumes that imagination, and therefore the arts, have an important role to play in sparking and strengthening people's individual and collective capacity to create fundamentally new socialecological systems.

Both 'imagination' and 'imaginaries' shape our sense of reality and possibility as we encounter the world. Imagination can be understood as a social and individual cognitive process by which we are able to conceptualize something beyond that which is immediately in front of us. It is a capacity that enables us to envision fantastical scenarios, but also more pragmatic possibilities for both what could happen and what should happen in reality (Bøttcher, 2020; Vadeboncoeur \& Vellos, 2016). Imagination is central to human agency because it orients people to future possibilities that require actions in the present (Appadurai, 1996; Zittoun \& Cerchia, 2013). At the same time, when people feel that a present situation is urgently untenable, it can stimulate a leap in their ability to imagine new scenarios, which then results in novel behaviours (Sannino, 2015).

Imaginaries, on the other hand, are less process and more structured, existing as deep, often unconscious, symbolic matrices that filter and mediate our experience of the world. As Kagan (2017) describes it, "the imaginary is like a cognitive and cultural hummus from which more articulate cultural constructs such as visions, narratives, discourses 
and utopias can grow and where they can take root" (p. 161). He points out that humans do not simply create and impose imaginaries on reality, but rather that they result from imaginative relational encounters between humans and the rest of the 'more-than-human' world. ${ }^{6}$ The term 'social imaginary' is therefore used to describe how groups of people collectively imagine and shape the parameters of societyin terms of aspirations and priorities and in terms of institutional and social structures (Taylor, 2004). Within the social imaginary, a plurality of paradoxical and conflicting interpretations or landscapes exists, but the overall sense of the possible is bounded by the scope of the imaginary.

Grounded in the above, the concept of the transformative imagination (as used by Galafassi, 2018) is a way of describing how individuals and groups can alter the social imaginary (or evoke different dimensions of it) by activating fundamentally new ways of seeing, sensing, feeling, encountering, and envisioning the world (Galafassi, 2018). Galafassi argues that transformative imagination supports change agency because it alters the underlying paradigms and worldviews that create the conditions for unsustainability.

Use of the terms paradigm or worldview, however, often implies that people have one dominant and consistent perspective that they apply in all situations. On the contrary, individuals, like societies themselves, are a plurality_not so coherent or consistent. Even if we have a strong, conscious preference for a particular worldview, the majority of people have multiple, often conflicting, conceptual frameworks (linked to different worldviews) that can be activated at any given time (Lakoff $\&$ Johnson, 1980). With this understanding, the term mindset is used here to describe a mental model or conceptual frame/metaphor that is triggered by a specific metaphorical stimulation. A specific mindset, when triggered, defines the overall 'common sense' regarding a specific situation and therefore the scope of possibilities for decision-making and sense-making. Studies about norms (Ariely \& Jones, 2008), framing (Lakoff \& Johnson, 1980), and priming (Molden, 2014; Nijland, 2016), suggest that, depending on the circumstances and relevant frames or

\footnotetext{
${ }^{6}$ More-than-human (coined by Abram, 1996) is used to describe other biological beings (e.g., animals, plants, fungi) and non-animate natural systems or entities (e.g., rivers, mountains, ecosystems).
} 
triggers, a different mindset, and therefore a different set of possibilities and norms, will arise, largely based on the way cognition is rooted in metaphorical thinking (Lakoff, 2010). It can be thought of as a pair of glasses that allows the wearer to see certain colours or opportunities more clearly. Therefore, transformative mindsets can be defined as specific cognitive lenses or frames that are helpful for orienting and motivating people specifically towards sustainability transformations (Pearson et al., 2018).

Emerging from this line of reasoning, I propose the concept of imaginative leadership; this can be broadly defined as the ability to influence, evoke, or shape the mental models, metaphors, and cultural narratives that people (both self and others) use to make sense of the world. My conceptualization is influenced by Bourdieu's (1991) understanding of symbolic power and Geertz's understanding of culture as a semiotic universe (1976). Lakoff (2010) makes two important points for understanding how imaginative leadership might support people's transformative capacity: (a) the inner dimensions are not static and consistent, but rather subject to ongoing fluctuation and emergent dynamics related to changing external and internal stimuli (also see Nijland, 2016); and (b) repetition of a particular metaphorical frame actually physically strengthens the synapses of specific neural circuits related to a particular ideological perspective (or mindset), which sets the parameters of possibility (in imagination and in action). Therefore, the imaginative leader develops the capacity to identify and evoke specific transformative mindsets (in both self and others) that activate conceptual frames with the potential to expand possibilities for transformative actions towards sustainability (see Pearson, 2021).

\section{Identifying Transformative Mindsets}

Creativity is an amoral capacity (Gardner, 1993; Katz, 2018): it can just as easily be used to design an astounding piece of machinery that destroys a forest as it can to spark a radical social-technical innovation that helps the forest and its inhabitants thrive. With this in mind, the methods used in the workshops were intended to evoke creativity for sustainability 
transformations by incorporating triggering metaphors and ideological language' (Lakoff, 2010) linked to specific mindsets. Therefore, the question became: which mindsets and which metaphors have the potential to spark mutually beneficial relationships between (and within) the human and more-than-human realms? And then: how can we intentionally evoke, anchor, and strengthen these mindsets and metaphors (in this context, through creative methods and generative engagements)?

During the exploration phase of the Action Hub, the co-design cohort identified a limited set of transformative mindsets (see Table 6.1) that was subsequently validated by the Imaginative Leadership co-designers. The list was derived via triangulation with input from literature, initial fieldwork (including expert interviews), and previous work experience related to sustainability transformations. It was not intended to be a definitive or comprehensive list of all transformative mindsets, but rather provide a reasonable starting point for experimentation. In the post-event reflection process, the conceptualization of these transformation mindsets was expanded and reconfigured, as presented in Section 6.4.

The concept of regenerative sustainability (see Table 6.1) deserves particular emphasis, because although it is designated as a mindset, the co-designers of both workshops also considered it as an overarching normative aim of sustainability transformations. In regenerative sustainability, human activities have the potential to have positive, beneficial impacts on the biosphere and all of its inhabitants, which is distinct from discourses on sustainability that primarily emphasize attempts to minimize harm (Mang \& Reed, 2020; Wahl, 2016). In fact, although the term sustainability is ubiquitous in academic literature, policy, and popular culture, its usefulness in supporting the scale of social transformation required by the complexity and urgency of global challenges is contested (Wahl, 2016). Herbert Girardet of the World Futures Council, for example, argues that the word sustainability is inadequate, and that regeneration or regenerative development is both a more realistic and a more compelling paradigm (Girardet, 2014). 
Table 6.1 Summary of the first iteration of 'transformative mindsets' that informed the design of the workshops and methods

\begin{tabular}{ll}
\hline Mindset & Core Concept \\
\hline Regenerative Sustainability & The possibility that human activity could \\
increase the biodiversity and health of \\
social-ecological systems, as distinct \\
from minimizing ecological or social \\
harm (Mang \& Reed, 2020; Wahl, 2016) \\
The ability to consider longer \\
perspectives (both past and future) \\
and multiple time-scales have the \\
potential to change the way of \\
conceptualizing both problems and \\
solutions (Boylston, 2019; Macy \& \\
Brown, 2014; Stewart, 2020) \\
De-centring anthropocentrism through \\
imaginative consideration of \\
'more-than-human' (Abrams, 1996; \\
Macy \& Brown, 2014) perspectives, \\
including biological beings (e.g., \\
animals, plants, fungi) and \\
non-animate natural systems or entities \\
(e.g., rivers, mountains, ecosystems) \\
Developing a sense of willing \\
responsibility and caring for specific \\
places, and with that an emotional \\
connection (Altman \& Low, 1992; \\
McEwan \& Goodman, 2010) \\
Sensitization to the reality of dynamic \\
complex systems and problems requires \\
an openness to uncertainty and a \\
willingness to experiment (Hollings, \\
2004; Kagan, 2011, 2017) \\
Care for Place
\end{tabular}

Note See Fig. 2 and table 3 in section $x x$ for revised list Source Own conceptualization (CCBY)

\section{Putting Theory in to Practice: Designing and Facilitating Creative Methods for Transformative Engagement}

Art is an adventure playground of the heart, where we can explore, discover, share and become who we are, in relative safety, alone and together-Francois Matarasso (2019: 43) 
To give context to the reflections and insights that follow, here I return to the process of designing and executing the two workshops. Some decisions made in the design and execution of the Action Hub carried over to the Imaginative Leadership, so are covered in more detail in the description of the former.

\section{Action Hub: Arts-based Methods for Transformative Design}

The cohort of co-designers for the Action Hub originally came together around a shared academic interest in theory and methodologies related to creative methods, but we also shared a more personal interest in using methods that make us (and our research participants) feel 'energized' and 'inspired'. Our collective objective was to put theory into practice and experiment 'exuberantly'. We were also motivated to share practical applications of our research that change-makers, action-researchers, and local leaders could use in their work.

As a first step for organizing our design, we collectively chose the change management framework of Theory U (see Scharmer, 2009) to structure the workshop (see Fig. 6.1 below). We selected Theory U for many reasons - expedient, intuitive, and logical. Expediently, it was already familiar to the co-design cohort; intuitively, it is easy to understand, communicate, and use even in its simplest form (as described here); and logically, it is backed by academic and philosophical rigour and the layers and nuances of the theory resonated with our overall AI and PAR approach. Moreover, Theory $U$ balances a clear linear structure with space for iterative looping, for spontaneity, and for indeterminacy. In several of the expert interviews, practitioners emphasized that establishing a stable, predictable framework for facilitation processes can help participants to leave their comfort zones and engage with unorthodox practices. It can also help consolidate outcomes and transitions into action. Leaving space for indeterminacy, on the other hand, is vital for cultivating serendipity, intuition, and lateral thinking, and therefore for sparking creativity, 'generative engagement', and new ways of perceiving. Theory $\mathrm{U}$ also highlights a balance between interpersonal processes of 


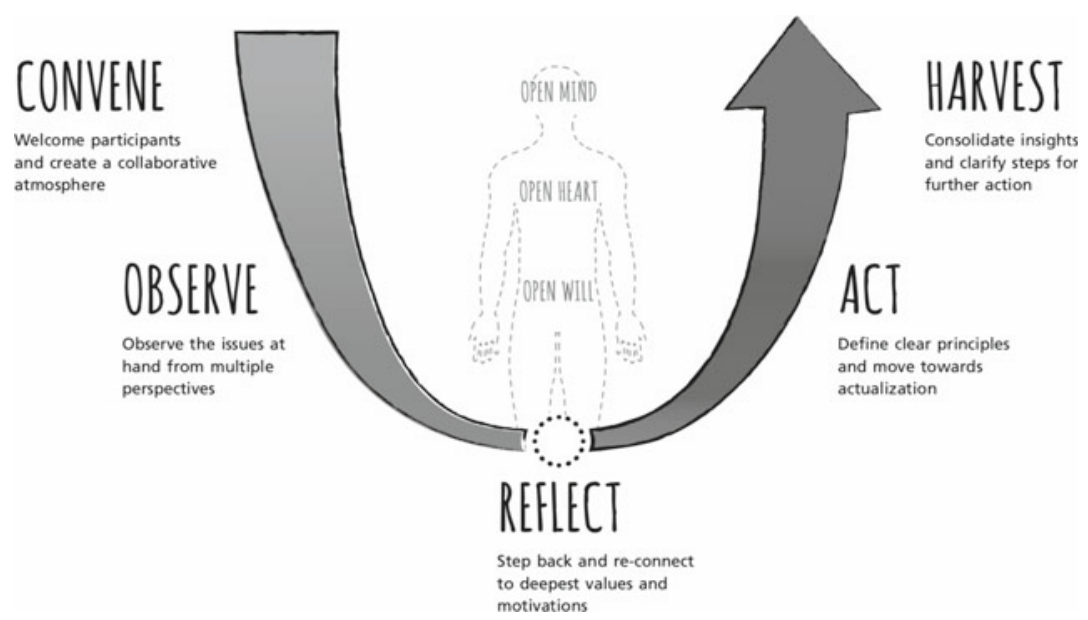

Fig. 6.1 Theory $U$ process of observing, reflecting, acting, harvesting (Source Pearson et al. [2018] as adapted from Scharmer [2009])

collaboration and individual or introspective processes of reflection. It acknowledges the importance and role of emotional intelligence and values, and is explicitly intended to open spaces of possibility, or in Scharmer's terms 'seeing with fresh eyes' and 'sensing the field'. Theory U also includes a phase for reflecting, ${ }^{7}$ or 'presencing'. This creates time for participants to intuitively connect with their deepest values and motivations; this is often missing from academic, community, governance, and corporate work on sustainability issues. Scharmer (2009) refers to this as 'the blind spot of leadership'.

In parallel with anchoring our design process in a clear structure, we identified key transformative mindsets (Table 6.1) that would be woven into our methods design and overall approach. To demonstrate the practical application of the methods, we decided to focus on three different specific design challenges (Table 6.2) based on real cases that were familiar to the co-designers. Next, before choosing, adapting, and

\footnotetext{
7 Note: As a strategic decision for communicating clearly and accessibly to our target audiences, we chose to change the term 'presencing' used by Scharmer (2009) and the Theory U practice community) to 'reflecting' to describe the bottom of the U.
} 
Table 6.2 Design challenges and stimulating questions: Action Hub

\begin{tabular}{|c|c|c|}
\hline Design Challenge & Description & Guiding Question \\
\hline \multirow[t]{2}{*}{$\begin{array}{l}\text { (1) Dismissed Military } \\
\text { Area in Italy }\end{array}$} & $\begin{array}{l}\text { Bottom-up cultural, } \\
\text { economic, and } \\
\text { ecological regeneration } \\
\text { of a dismissed military } \\
\text { area in Northern Italy }\end{array}$ & $\begin{array}{l}\text { (Group A) How can we } \\
\text { imagine the distant } \\
\text { future? }\end{array}$ \\
\hline & & $\begin{array}{l}\text { (Group B) How can the } \\
\text { dismissed military area } \\
\text { include } \\
\text { more-than-human } \\
\text { perspectives? }\end{array}$ \\
\hline $\begin{array}{l}\text { (2) Abandoned } \\
\text { Farmstead in the } \\
\text { Netherlands }\end{array}$ & $\begin{array}{l}\text { Re-imagining the } \\
\text { potential uses of an } \\
\text { abandoned farm in } \\
\text { Overijssel, The } \\
\text { Netherlands }\end{array}$ & $\begin{array}{l}\text { (Group A) How can the } \\
\text { farm regeneration } \\
\text { project include } \\
\text { more-than-human } \\
\text { perspectives? } \\
\text { (Group B) How is a farm } \\
\text { like a church? }\end{array}$ \\
\hline $\begin{array}{l}\text { (3) Moving the city } \\
\text { centre in Kiruna } \\
\text { Sweden }\end{array}$ & $\begin{array}{l}\text { Moving and re-designing } \\
\text { a new city centre in } \\
\text { Kiruna Sweden due to } \\
\text { the expansion of } \\
\text { mining operations }\end{array}$ & $\begin{array}{l}\text { How can the new town } \\
\text { square incorporate } \\
\text { more-than-human } \\
\text { perspectives? }\end{array}$ \\
\hline
\end{tabular}

Note Challenges 1 and 2 were split into two groups with different guiding questions. Challenge 3 was addressed by only one group Source Own conceptualization (CCBY)

designing specific methods, we identified the overall goals and stimulating questions related to each design challenge, and each phase of the Theory U. Eventually, we settled on a design that enabled 5 small groups of 4-6 people to follow a set structure in terms of timing, but within the context of different pre-prepared design challenges, different stimulating questions, employing different creative methods, and emphasizing different transformative mindsets within each group.

The creative methods were then designed with the intention to root and anchor transformative mindsets via sticky metaphors and multisensory experiential learning, making them more auto-accessible and increasing participants' self-efficacy. At the same time the methods were intended for uptake by the participants - to support them in using creative methods (based in transformative mindsets) in their own research and work. 
To illustrate the workshop in more concrete terms, Table 6.3 outlines the Dismissed Military Area challenge, including the methods used and the related transformative mindsets. Figure 6.2 shows some of the methods in action.

In the execution phase, we made sure that materials were wellorganized for smooth transitions between activities, that instructions were available verbally and in writing, and that the room was aesthetically pleasing and had a welcoming atmosphere. We used nature-based images and objects (e.g., flowers, pinecones, rocks) to stimulate a sense of biophilia.

In order to get feedback on the workshop, three academic colleagues acted as participant-observers in the smaller groups and reported back their observations. In addition, each of the table facilitators reported on their experience and the 'harvest' with their respective participant groups, and we sent out a follow-up survey. Overall, the feedback was overwhelmingly enthusiastic, with some small technical suggestions (more time being the primary request) and ideas for further experimentation, such as putting more emphasis on establishing trusting group dynamics.

\section{Imaginative Leadership: Co-producing with Nature and Communities (for Frontline Staff in Welsh Government)}

Wales has been a global leader in creating leading-edge policy agendas to support sustainability transformations (Jones et al., 2020), and many people are now working to figure out how to accelerate implementation in various arenas (see Giambartolomei et al., this book). The co-designers of the Imaginative Leadership workshop were all interested in supporting the Welsh agenda, specifically with leadership development in the Welsh Government.

As with the development of the Action Hub, before designing specific methods, we started with the overall objectives of the workshop from the perspective of the participants and different participating stakeholders. We aimed to (a) introduce the concept of creative methods and transformative mindsets, (b) demonstrate the use (and usefulness) of specific 


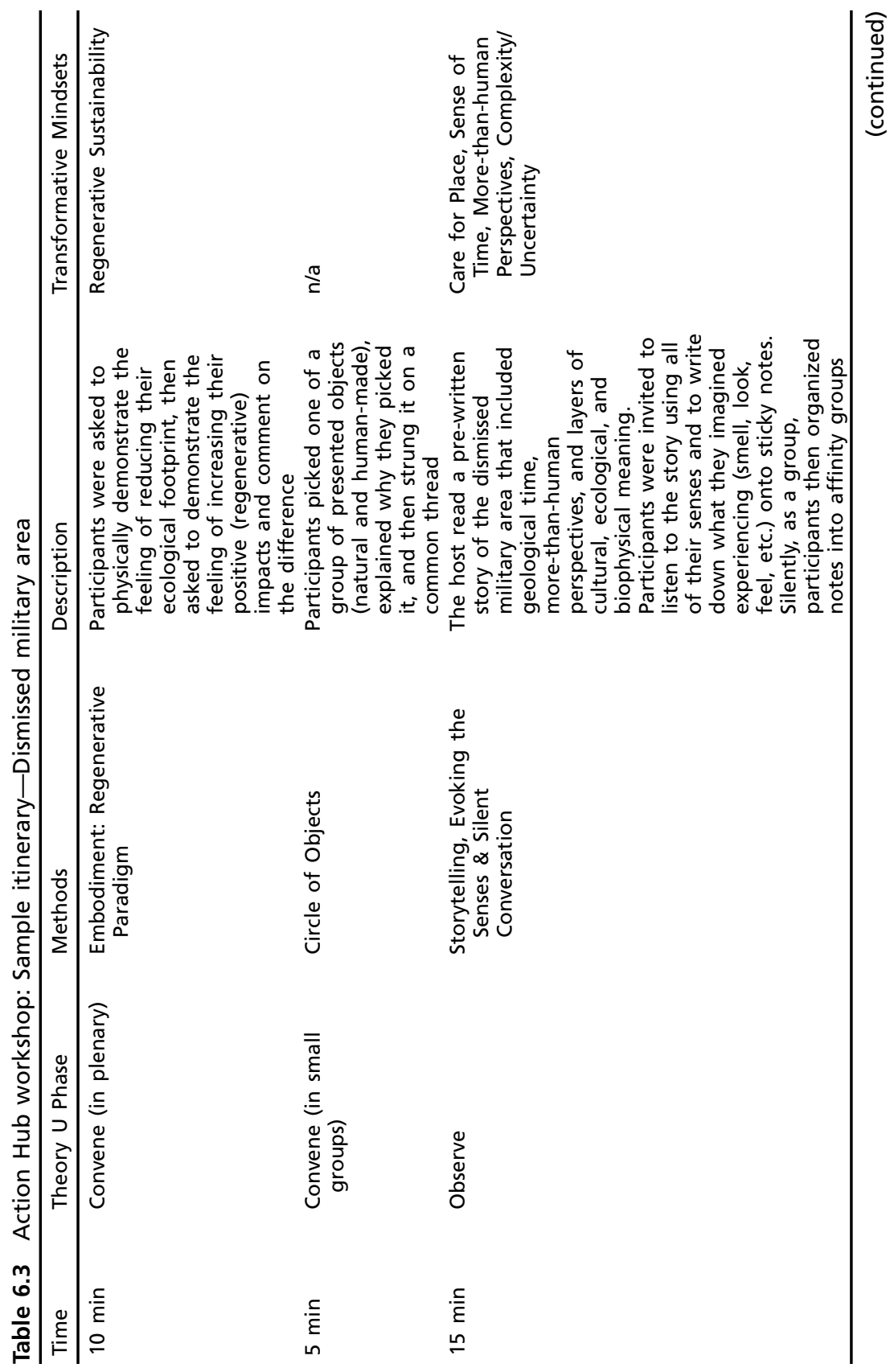




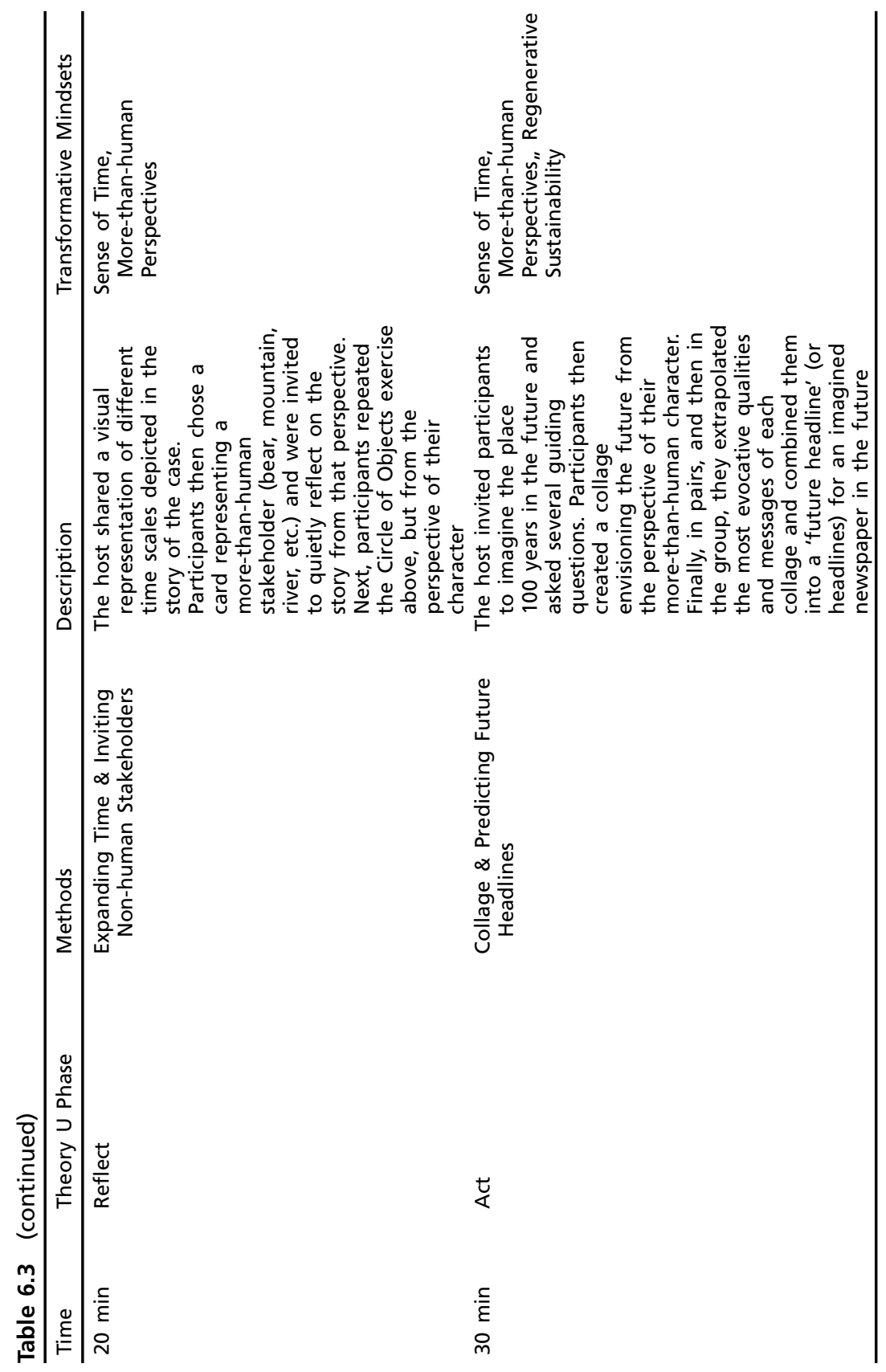




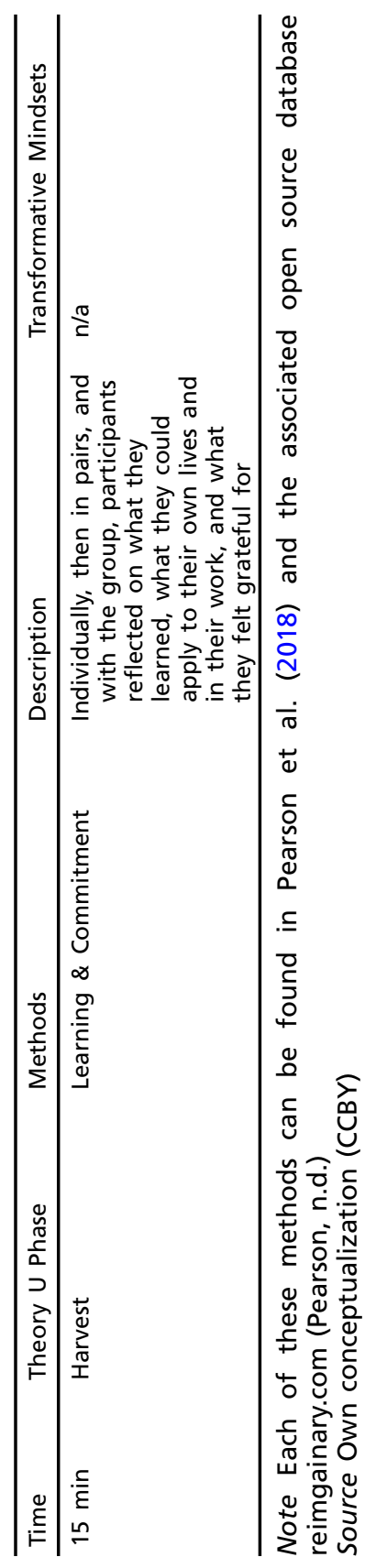



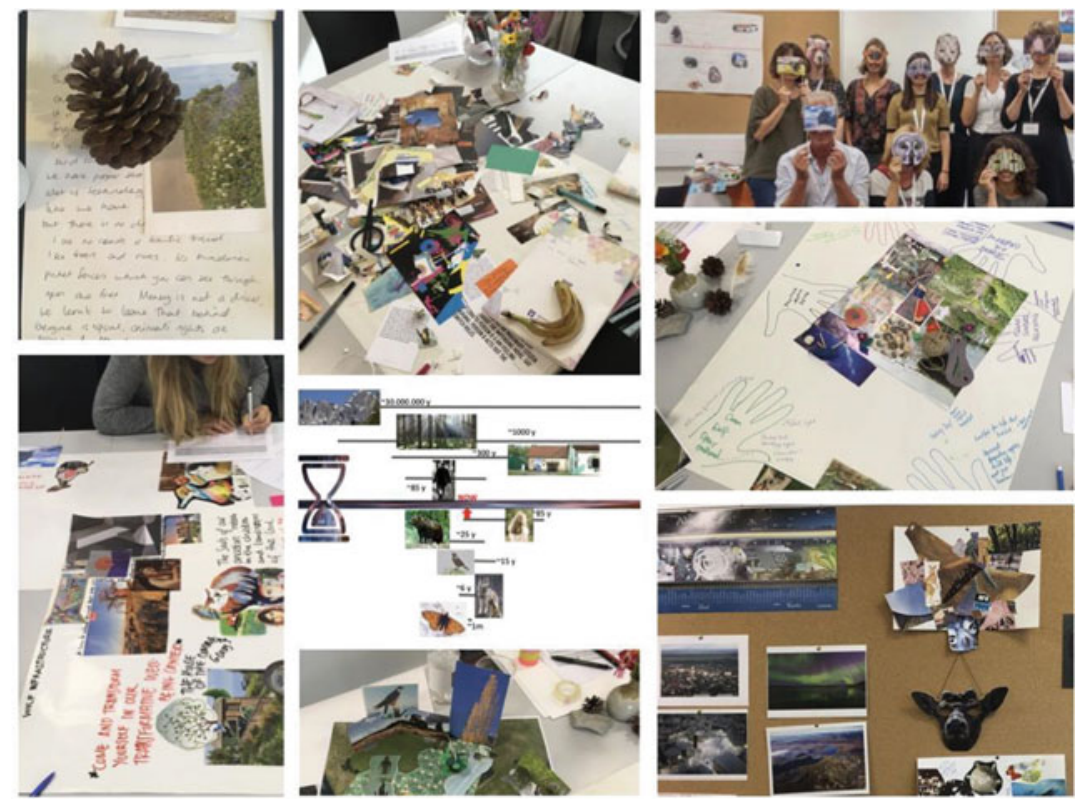

Fig. 6.2 Photographs from Action Hub (Source Photographs taken by Action Hub co-designers with permission)

creative methods for uptake by participants to employ in their own projects, and (c) provide the opportunity for participants to work on actual challenges from their work through the lens of specific transformative mindsets. With consensus from the Imaginative Leadership co-design group, the structure of Theory $\mathrm{U}$ was carried over from the Action Hub.

We used a hypothetical design challenge based on the town of Treherbert in Wales, which the local co-designers identified as emblematic of communities whose economic livelihood used to depend on the now-defunct mining sector. In the post-mining era, many towns and villages have struggled to re-invent themselves and re-define economic (and ecological) well-being for themselves. For the first half of the day, the workshop design focused on re-framing possible futures for Treherbert, evoking an expanded sense of time and more-than-human perspectives, using methods such as the Timeline of Transformation, Storytelling, and Inviting More-Than-human Stakeholders (Pearson 
et al., 2018). For the second half of the day, building on these new perspectives, we structured a form of peer-to-peer mentoring that looked at specific challenges faced by participants, while still including morethan-human stakeholders.

The Action Hub event venue was predetermined, but for Imaginative Leadership we were able to choose the locations. Based on her experience in place-responsive performative arts and sustainability, the artist/facilitator emphasized the importance of establishing relationality between the physical space of the workshop (including its history and its symbolic/cultural dimensions) and the design and methodology of the workshop. We looked for spaces that had access to nature, that aligned with our sustainability values (i.e., minimal disposable plastics, availability of sustainability produced food), and that had some cultural/symbolic significance. Once again, we put attention on creating a warm, welcoming ambiance in setting up the room. We also provided a participant workbook that included instructions for each method, key references, and space to take notes.

Feedback from participants was gathered during the harvesting phase of the event and was, again, overwhelmingly enthusiastic. Co-designers and two colleagues acted as participant-observers, and I subsequently conducted follow-up interviews (together with many informal conversations) with co-designers in the months following the workshop.

\section{Acknowledging Limits}

Here I highlight three decisions that limited the scope of these experiments in substantive ways. First, the duration of the workshops was limited to 90 minutes and a full day respectively, with no follow-up or ongoing engagement. This was due to the constraints of the context in which the research took place, and was not an intentional part of the design. Sustained generative engagements, such as extended ongoing training in which people meet regularly over a longer period of time or multi-day intensive 'collective artist residencies' (Eernstman et al., 2021), could involve more iterative processes and yield rich data and 
more detailed insights about the potential of creative methods to support transformative mindsets.

Second, this research was deliberately focused on increasing the selfefficacy and leadership capacity of people already engaged with sustainability. This decision stemmed from my research parameters, but also from ethical and practical considerations. Ethically, there is a fine line between persuasion and manipulation (Noggle, 2020), which I preferred not to approach, and, practically, within the short time scope of the engagements, starting from a place of common understanding and shared values saved time and effort in terms of setting the groundwork for willing and enthusiastic participation. In the future, it would be interesting to invite people with less familiarity or commitment to sustainability issues to experiment with some of these practices.

Third was the decision to avoid controversial topics or areas of conflict and avoid processes of decision-making. This was intentional; it allowed for a relatively simplistic approach to designing and facilitating the workshops and enabled us to focus on developing our concept of using creative methods to support/spark transformative mindsets. Moreover, it was not realistic or appropriate to surface deeper, potentially traumatic issues given the time constraints. Within different parameters, however, creative methods that are rooted in the deeper common values of participants have the potential to engage generativity with the reality of conflict, power-dynamics, eco-anxiety, and other hidden dimensions such as conflicting goals, values, and agendas (e.g., the value of surfacing conflict in social learning for sustainability, Wals \& Heymann, 2004).

\section{Putting Practice into Theory: Another Look at Transformative Mindsets for Imaginative Leadership}

The initial list of transformative mindsets, while incomplete, provided a jumping off point for experimentation. Upon revisiting them during the post-workshop reflection process, both co-design cohorts agreed that they were indeed useful and valuable and that they stretched our own 
creativity and transformative imagination. They supported our novel approach to facilitating generative engagements rooted in creativity for transformations towards regenerative sustainability. At the same time, we identified areas for fine-tuning and some gaps. The revised list (see Fig. 6.3) proposes a new starting point for further experimentation and the expansion of a framework for supporting imaginative leadership through generative engagements and creative methods. Notably, the list, as it is presented here, is meant for uptake in the field, and is therefore framed for simplicity and clarity with the lay reader in mind. Moreover, it is with humility that I emphasize that each of these mindsets has been studied extensively across disciplines and each represents a vast arena of interconnected literature; they have been framed in many different ways in literature and in practice. In accordance with the parameters of this chapter, the following discussion represents only a brief and limited

\section{Transformative Mindsets for Regenerative Sustainability}

\begin{tabular}{|l|l|}
\hline (1) Regenerative Sustainability & (2) Sense of Time \\
\hline (4) Cense of Time & (4) More-than-human Insights \\
\hline (5) Complexity/Uncertainty & (5) Expanded Spheres of Caring \\
\hline (3) More-than-human Perspectives & (6) Dynamic Complexity \\
\hline
\end{tabular}

Fig. 6.3 Revised list of transformative mindsets (Source Own conceptualization [CCBY]) 
summary of each (for a more detailed account of each, see Pearson, 2021).

First, regenerative sustainability (1) was validated by both co-designers and participants as a foundational concept for imaginative leadership. As a normative aim and as a transformative mindset, it represents a generative evolution in the concept and application of sustainability (Mang $\&$ Reed, 2020; Wahl, 2016). The importance of sense of time and consideration of more-than-human perspectives were also confirmed. Although participants worked in the field of sustainability, in general they found it challenging to imagine 100 years or even 20 years into the future and they appreciated the chance to reflect through the lens of multiple time-scales. Likewise, people valued the opportunity to engage with the design challenges and their own projects through an imaginatively more-than-human lens.

The more-than-human can be considered empathically and ethically (Abrams, 1996; de La Bellacasa, 2017), in planning and decision-making (Macy \& Brown, 2014) and from a legal rights-of-nature perspective (Boyd, 2017), but also more instrumentally as inspiration for innovation. The practice of biomimicry (Benyus, 1997), for example, aims to learn from and appreciate the design intelligence (" 3.8 billion years of research and development") inherent in natural systems as input for innovations, not only for technology and infrastructure, but also for social and economic innovations (i.e., what could an economic system learn from a forest?). The term more-than-human 'perspectives' was therefore modified to the more expansive term more-than-human 'insights' (3).

The mindset of caring for place in the initial list was indeed a useful lens for designing methods that evoke an emotional, sensory connection to specific places. Upon reflection, however, caring as a stand-alone concept was woven into so many dimensions of the design process that it emerged as foundational to our approach on multiple levels. Therefore, we split this mindset into its two components: place-based (4) and expanded spheres of care (5). A place-based lens (see Massey, 2015) emphasizes an attentiveness to the specificity, assemblage of relationships, and the 'situatedness' of what makes a place a place (biophysical, symbolic, cultural, relational, etc.); places are 'where things happen' in terms of sustainability transformations (Horlings et al., 2020). It 
also implies a felt mutuality or attachment; this can be both affective/emotional (Altman \& Low, 1992; McEwan \& Goodman, 2010) and pragmatic, appreciating our (inter) dependence with tangible and intangible place-based resources, for example (Horlings et al., 2020).

Expanded spheres of care (5) highlights both an expanding circle (Singer, 1981/2011) of ethical concern (who is being cared for) and the attitudes and practices for expressing care (i.e., how to care). The expanded sphere moves beyond self and immediate kin to include humans 'others', the more-than-human, and even future (and past) generations. A broad scope of caring is seen as an essential component of leadership for regenerative sustainability (see Schein, 2017 for an overview of the caring/ecological worldview). ${ }^{8}$ In terms of attitudes and practices, during the workshops we aimed to be attentive to and inclusive of diverse (and overlooked) voices and perspectives and to respectfully support the physical and mental well-being of participants (and co-designers). Notably, we observed the value of a caring intentionality in designing the workshop 'container', i.e., the physical place (from acoustics to aesthetics to temperature and light), the relationality among the participants and facilitators, and other, often 'invisible' supportive elements such as the food or even the organization of materials.

In our initial list, complexity and uncertainty were considered as one mindset. Both were present and played important roles in shaping our approach, but in practice they were quite distinct. Much has been written about how the ability to respond to dynamic complexity ${ }^{9}$ (5) is an underdeveloped capacity (Kagan, 2011; Schein, 2017). Complex adaptive living systems (a watershed for example) are often not predictable or rationally knowable in terms of observable relationality between cause and effect as they are in 'complicated' mechanistic systems (Burns et al., 2015; Holling, 2004); they therefore require a probing and experimental approach to problem solving. In conceptualizing complex living systems,

\footnotetext{
8 Moriggi et al. (2020) propose an in-depth framework of caring in relation to sustainability transformations that includes ethically informed practices, emotional awareness, and relational response-ability (Haraway, 2016) i.e., the ability to responsibility respond to the context at hand.

${ }^{9}$ Burns et al. (2015), for example, identify complex living systems as an overarching paradigm in sustainability leadership (in opposition to the Newtonian mechanistic worldview).
} 
queer ecology adds another dimension, in which diversity is appreciated, and essentializing or reductionist categories placed on self and others are problematized ('freaked out'), and instead considered more fluidly (Kagan, 2011, 2017).

Uncertainty (6), on the other hand, can be thought of as an essential attitude in the face of complexity. The capacity to be open to 'not knowing' emerged as a golden thread frequently emphasized by practitioners, artists, participants, and the co-designers in both projects and in literature (see Kagan, 2017). It can be linked to the ability to look at problems through new imaginative perspectives (e.g., more-thanhuman), to weakening the static hierarchy of the expert/audience duality, to opening the scope of possibilities for action, to communicating in new ways, and to re-defining constellations of collaboration (Arora, 2019; Clampitt et al., 2001; Kagan, 2017). Uncertainty can also be characterized as 'beginner's mind'; this has been central to many mindfulness traditions and, in modern applications, has been applied widely, for example in diagnosis and care in medical practices (Epstein, 2003) and in pedagogy (Kochhar-Lindgren, 2001). In contrast to a static destination, Kagan (2011) frames sustainability as a dynamic 'search process', emphasizing that people do not fully understand complex living systems, or even what a regenerative or sustainable society should or could look like in the future.

In addition to revising the original list of transformative mindsets, during the design, execution, and reflection processes two key gaps became evident. First, was the importance of a holistic approach (7) to knowledge, places, and people. A holistic approach takes into account context and relationality, including historical, biophysical, cultural, social, psychological, and symbolic dimensions; it acknowledges both the embeddedness and embodiedness of both social imaginaries and physical realities (Haraway, 2016). ${ }^{10}$ Through this lens, knowledge must be grounded in context and specific places (Horlings et al., 2020). Importantly, all participants (in the broadest sense possible) were considered with a 'whole-person approach' that considered their well-being,

\footnotetext{
10 See Warm Data Lab (n.d) for a promising approach to addressing the deep relationality and complexity inherent in social science research.
} 
thoughts, emotions, motivations, perceptions of place, and constellation of relationships through time. ${ }^{11}$ From a holistic perspective, the methods themselves were embedded in the context of the process (or the 'container'). A holistic approach can be woven into the fabric of an event, as demonstrated in the process of incorporating a relational response to our event location in Imaginative Leadership. ${ }^{12}$ In addition, the twin concepts of mutuality and interdependence are vital to a holistic approach and they were emphasized repeatedly in our design process from a philosophical perspective. Notably, we did not link the concept of interdependence to specific methods-perhaps because it was not a part of the initial list. The concept of interdependence has long roots in indigenous and non-occidental philosophies, knowledge, and worldviews (Avalos Cisneros, 2015), but has only more recently been mainstreamed in western positivist sciences such as ecology (Callenbach, 2008).

The second gap that we identified was a mindset of intersectionality (8); this is not only foundational for supporting transformational change, but must also be explicitly highlighted. It is crucial to strengthen our collective and individual conceptual frames that connect social issues, such as racism, gender issues, wealth inequality, colonialism, or oppressive violence and dominance-based power dynamics with issues of ecological destruction and degradation. ${ }^{13}$ Moving away from an anthropocentric perspective can help to disrupt default assumptions about humans' right to dominate other species (as in the workshops described in this chapter), but within the scope of our workshops and methods, we did not address the topic directly. Indeed, there is potential for exploring and surfacing these connections with a guided application of creative methods within the conceptual framework of imaginative leadership. For a critical literature review on intersectionality and sustainability education see Maina-Okori et al. (2018), an intersectional perspective on

\footnotetext{
11 'Whole person approach' has been applied in many contexts, such as medical care (Thomas et al., 2018) and pedagogy (Fadeeva et al., 2010).

12 It also points to research about the way metaphors can be embodied, or grounded in physical environments.

13 Environmental racism and the genocide of indigenous people, for example, cannot, in reality, be separated from the so-called 'ecological dimensions' of unsustainability, such as biodiversity loss and pollution/degradation of natural environments.
} 
climate change see Kaijser and Kronsell (2014), and reflection on intersectionality in light of the life and murder of Berta Cáceres see Méndez (2018).

The revised list of mindsets is summarized in Table 6.4, together with a short statement of key transformative aspects and suggestions for further reading.

Table 6.4 Revised transformative mindsets

\begin{tabular}{ll}
\hline Mindset & Transformative Aspect \\
\hline (1) Regenerative Sustainability & From minimizing harm to generating \\
& resilience and vitality for the biosphere \\
& and its inhabitants (Mang \& Reed, 2020; \\
& Wahl, 2016) \\
& From chronic short-termism, to an \\
& expanded ability to think in multiple \\
& time-scales, especially incorporating \\
(2) Sense of Time & long-term perspectives (Macy \& Brown, \\
& $2014 ;$ Boylston, 2019; Steward, 2020) \\
& From anthropocentrism to attentively, \\
& imaginatively, and ethically including \\
& more-than-human perspectives in \\
(3) More-than-human Insights & processes of knowledge co-creation \\
& (Abrams, 1996; Benyus, 1997; Boyd, \\
& 2017; de La Bellacasa, 2017) \\
& From universalist approaches to \\
(4) Place-based & conplacement'-grounded and \\
& contextualized and emerging from a \\
& relational approach to place-specificity \\
& (Massey, 2005; Macnamara, 2012; \\
Horlings et al., 2020) \\
Expanded spheres of ethical concern for \\
humans, places, and our ecological \\
(5) Expanded Spheres of Care \\
selves (de La Bellacasa, 2017; Moriggi \\
et al., 2020; Schein, 2017; Singer, \\
1981/2011; Haraway, 2016) \\
Limitations of mechanistic mindset for \\
problem solving and knowledge \\
creation; De-essentializing living systems, \\
diversity and queer conviviality \\
(Boylston, 2019; Burns et al., 2015; \\
Holling, 2004; Kagan, 2011, 2017) \\
\hline
\end{tabular}


Table 6.4 (continued)

\begin{tabular}{ll}
\hline Mindset & Transformative Aspect \\
\hline (7) Uncertainty & From a 'need-to-know' model of expertise \\
& to comfortability with not knowing; \\
& framing sustainability as 'a search \\
& process' instead of a destination (Arora, \\
& $2019 ;$ Kagan, 2017; Clampitt et al., 2001; \\
& Epstein, 2003; Kochhar-Lindgren, 2001) \\
& From abstracted, to embedded (physically, \\
& relationally, and semiotically), situated \\
and contextual (often place-based), and & interdependent (from \\
(8) Holistic Approach & compartmentalization to mutuality). \\
& Includes a 'whole-person' approach to \\
& design and facilitation (Avalos Cisneros, \\
& $2015 ;$ Callenbach, 2008; Fadeeva et al., \\
& $2010 ;$ Haraway, 2016; Thomas et al., \\
& 2018) \\
The way humans interact with other \\
species and the biosphere with violence \\
and extractive motivations is intertwined \\
with dysfunctions in intra-human \\
dynamics (Kaijser \& Kronsell, 2014; \\
Maina-Okori et al., 2018; Méndez, 2018)
\end{tabular}

Source Own conceptualization (CCBY)

\section{Conclusion}

The survival of civilization and the well-being of humankind in the future will require a dramatic shift in the dominant cultures of global society-a veritable cultural renaissance-Boyden (2001: 112)

The poet, philosopher, artist, and storyteller in each of us shape our sense of what is important, worthwhile, and possible. When we are touched and moved by the emotional resonance or compelling aesthetic of an artistic endeavour, new pathways emerge in the landscapes of our imagination, which counters the stifling, fatalistic perception that 'there is no alternative'. Within the broad landscape of our collective social imaginary, specific worldviews, metaphors, and mental models invisibly "channel attention, filter information, categorize experience, anchor interpretation, orient learning, establish moods, secrete norms, 
and legitimates narratives, ideologies, and power structures" (Gladwin et al., 1997, p. 245). In fact, the structures, institutions, and technologies created and deployed by a society reflect its culture, its worldview, and how it understands and engages with natural and more-than-human systems (Mang \& Reed, 2020). Imaginative leadership through the arts can nourish a cultural renaissance towards regenerative sustainability by sparking new stories, metaphors, and practices that support transformative mindsets and open new spaces of possibility.

The design of generative engagements that employ creative methods, which are consciously and explicitly linked to transformative mindsets, is one arena among many for playful experimentation. It is worth re-emphasizing that because mindsets are not constant, the point of this experimentation is to practice deliberately evoking specific mindsets, based on people's own values.

The loose experimental nature of the learning process recounted in this chapter leaves significant room for future exploration and discovery. The revised list of transformative mindsets reflects the direct experience of the co-designers and is intended to act as a starting point for the next iteration of exploration and experimentation with creative methods, the transformative imagination, and the development of imaginative leadership. Future research could more fully consider:

- the quality and typologies of participation during the design process and during the event;

- the role of the 'container' and how it connects to a holistic approach and a deep commitment to caring as practice;

- the validity, interpretation, and range of transformative mindsets could be co-explored and contextualized with participants or compared with other aligned frameworks.

On one hand, it would be interesting to design a research experiment that looks at the influence of specific mindsets on tangible design outcomes in processes of planning or the design of specific initiatives. On the other, it could be fruitful to problematize and explore the instrumentalism of creative approaches and the focus on solution-oriented strategic 
development, in contrast to more open-ended and ontological explorations. Creative methods are certainly not a panacea and they can be applied more or less skilfully, and used more or less appropriately in different contexts, for different aims; it would certainly be illuminating to look in more depth at how and when creative methods fail or even backfire and increase resistance and conflict (see van der Vaart et al., 2019).

Although sustainability is an ongoing 'search process' (Kagan, 2011) rooted in productive uncertainty, transformations towards just and ecologically healthy societies will always involve a reflection on what we value, accept, reject, love, care for, are passionate about, what we find just, fair, and sensible. They are also shaped and constrained by path-dependent contexts and systemic structures and accepted norms. As Herbert Marcuse has said: "The truth of art lies in its power to break the monopoly of established reality to define what is real...Art cannot change the world, but it can contribute to changing the consciousness and drives of the men and women who could change the world" (Marcuse, 1978: 9/33).

Acknowledgements This research was supported by SUSPLACE, a Marie Skłodowska-Curie Actions Innovative Training Network funded by the European Union's Horizon 2020 research and innovation programme under the Marie Skłodowska-Curie grant agreement No. 674962.

\section{References}

Abram, D. (1996). The spell of the sensuous: Perception and language in a morethan-human world. Vintage.

Ajzen, I. (1991). The theory of planned behavior. Organizational Behavior and Human Decision Processes, 50(2), 179-211.

Altman I., \& Low S. M. (Eds) (1992). Place attachment. Plenum Press.

Appadurai, A. (1996). Disjuncture and difference in the global cultural economy. In Modernity at large: Cultural dimensions of globalization (pp. 2747). University of Minnesota. 
Ariely, D., \& Jones, S. (2008). Predictably irrational. New York, NY: Harper Audio.

Arora, S. (2019). Admitting uncertainty, transforming engagement: Towards caring practices for sustainability beyond climate change. Regional Environmental Change, 19(6), 1571-1584.

Avalos Cisneros, N. (2015). Interdependence as a lifeway: Decolonization and resistance in transnational native American and Tibetan communities (Doctoral dissertation, UC Santa Barbara).

Belfiore, E., \& Bennett, O. (2008). The social impact of the arts-An intellectual history. Palgrave MacMillan.

Benyus, J. M. (1997). Biomimicry: Innovation inspired by nature. Morrow.

Blumer, H. (1954). What is wrong with social theory? American Sociological Review, 19(1), 3-10.

Bøttcher, L. (2020). Supporting unusual development through moral imagination. Learning, Culture and Social Interaction, 100384.

Bochner, A. P. (2009). Warm ideas and chilling consequences. International Review of Qualitative Research, 2(3), 357-370.

Boyd, D. R. (2017). The rights of nature: A legal revolution that could save the world. ECW Press.

Boyden, S. (2001). Nature, society, history and social change. Innovation: The European Journal of Social Science Research, 14(2), 103-116.

Boylston, S. (2019). Designing with society: A capabilities approach to design, systems thinking and social innovation. Routledge.

Bourdieu, P. (1991). Language and symbolic power. Harvard University Press.

Burns, H., Diamond-Vaught, H., \& Bauman, C. (2015). Leadership for sustainability: Theoretical foundations and pedagogical practices that Foster change. International Journal of Leadership Studies, 9(1).

Candy, L. (2006). Practice-based research: A guide. CCS report, 1(2).

Callenbach, E. (2008). Interdependence. In Ecology, revised and expanded (pp. 83-85). University of California Press.

Clampitt, P., Williams, M. L., \& DeKoch, R. (2001). Embracing uncertainty: The executive's challenge. Journal of Change Management, 2(3), 212-228.

Cohen, I. R., \& Harel, D. (2007). Explaining a complex living system: Dynamics, multi-scaling and emergence. Journal of the Royal Society Interface, 4(13), 175-182.

Cooperrider, D. L., \& Whitney, D. (2001). A positive revolution in change: Appreciative inquiry. Public Administration and Public Policy, 87, 611-630. Dewey, J. (1922). Human nature and conduct: An introduction to social psychology. Henry Holt 
Dewey J. (1934/2005). Art as experience. Penguin.

Eernstman, N., van Boeckel, J., Sacks, S., \& Myers, M. (2012). Inviting the unforeseen: A dialogue about art, learning and sustainability (pp. 201-212). Wageningen Publishers.

Eernstman, N., \& Wals, A. E. (2013). Locative meaning-making: An artsbased approach to learning for sustainable development. Sustainability, 5(4), 1645-1660.

Eernstman, N., Pearson, K. R., de Vrieze, A., Wals, A., \& Bjurström, A. E. (2021). Designing collective artist residencies: Cultivating imaginative disruptions and lightheartedness in times of gravity. Arts and Interdisciplinary Research, (3), 17-34.

Eisner, E. W. (2002). The arts and the creation of mind. Yale University Press.

Epstein, R. M. (2003). Mindful practice in action (I): Technical competence, evidence-based medicine, and relationship-centered care. Families, Systems, \& Health, 21(1), 1.

Fadeeva, Z., Mochizuki, Y., Podger, D. M., Mustakova-Possardt, E., \& Reid, A. (2010). A whole-person approach to educating for sustainability. International Journal of Sustainability in Higher Education.

Galafassi, D. (2018). The transformative imagination: Re-imagining the world towards sustainability (Doctoral dissertation, Stockholm Resilience Centre, Stockholm University).

Gardner, H. (1993). Creating minds. Basic Books.

Gardner, H. (2011). Frames of mind: The theory of multiple intelligences. Hachette.

Geertz, C. (1976). Art as a cultural system. Modern Language Notes, 91(6), 1473-1499.

Geertz, C. (1998). Deep hanging out. The New York Review of Books, 45(16), $69-72$.

Gergen, K. (2009). Relational being: Beyond self and community. Oxford University Press.

Girardet, H. (2014). Creating regenerative cities. Routledge.

Gladwin, T. N., Newberry, W. E., \& Reiskin, E. D. (1997). Why is the northern elite mind biased against community, the environment, and a sustainable future? Environment, Ethics, and Behaviour, 234-247.

Groth, C. (2017). Making sense through hands: Design and craft practice analysed as embodied cognition. Aalto University, Helsinki.

Greene, M. (1995). Releasing the imagination: Essays on education, the arts, and social change. Jossey-Bass. 
Gulliksen, M. S. (2017). Making matters? Unpacking the role of practical aesthetic making activities in the general education through the theoretical lens of embodied learning. Cogent Education, 4(1), 1415108.

Hammond, C., Gifford, W., Thomas, R., Rabaa, S., Thomas, O., \& Domecq, M. C. (2018). Arts-based research methods with indigenous peoples: An international scoping review. AlterNative: An International Journal of Indigenous Peoples, 14(3), 260-276.

Haraway, D. J. (2016). Staying with the trouble: Making kin in the Chthulucene. Duke University Press.

Hawkins, H., Marston, S. A., Ingram, M., \& Straughan, E. (2015). The art of socioecological transformation. Annals of the Association of American Geographers, 105(2), 331-341.

Hedlund-de Witt, A. (2013). Worldviews and their significance for the global sustainable development debate. Environmental Ethics, 35, 133-162.

Holling, C. S. (2004). From complex regions to complex worlds. Ecology and Society, 9(1).

Horlings, L. G. (2017). The role of artists and researchers in sustainable placeshaping. Culture in Sustainability, 131.

Horlings, L. G., Roep, D., Mathijs, E., \& Marsden, T. (2020). Exploring the transformative capacity of place-shaping practices. Sustainability Science, 15(2), 353-362.

Hulme, M. (2011). Meet the humanities. Nature Climate Change, 1(4), 177179.

Isaksen, S. G., Dorval, K. B., \& Treffinger, D. J. (2010). Creative approaches to problem solving: A framework for innovation and change. Sage.

Jones, N. A., Ross, H., Lynam, T., Perez, P., \& Leitch, A. (2011). Mental models: An interdisciplinary synthesis of theory and methods. Ecology and Society, 16(1), 46-46.

Jones, R., Goodwin-Hawkins, B., \& Woods, M. (2020). From territorial cohesion to regional spatial justice: The well-being of future generations act in Wales. International Journal of Urban and Regional Research, 44(5), 894-912.

Kagan, S. (2011). Art and sustainability: Connecting patterns for a culture of complexity, Transcript Verlag.

Kagan, S. (2017). Artful sustainability: Queer-convivialist life-art and the artistic turn in sustainability research. Transdisciplinary Journal of Engineering \& Science, 8.

Kaijser, A., \& Kronsell, A. (2014). Climate change through the lens of intersectionality. Environmental Politics, 23(3), 417-433. 
Katz, L. (2018). Dark dreams and malign creativity. Knowledge Cultures, 6(02), 64-75.

Kearns, L. L. (2015). Subjects of wonder: Toward an aesthetics, ethics, and pedagogy of wonder. Journal of Aesthetic Education, 49(1), 98-119.

Kepes, G. (1972). Arts of the environment. Aidan Ellis.

Kochhar-Lindgren, G. (2001). Beginner's mind: Opening the open in the classroom. Pedagogy, 1(2), 410-415.

de La Bellacasa, M. P. (2017). Matters of care: Speculative ethics in more than human worlds (Vol. 41). University of Minnesota Press.

Lakoff, G. (2010). Why it matters how we frame the environment. Environmental Communication, 4(1), 70-81.

Lakoff, G., \& Johnson, M. (1980). Metaphors we live by. University of Chicago press.

Lertzman, R. (2015). Environmental melancholia: Psychoanalytic dimensions of engagement. Routledge.

Macnamara, L. (2012), People \& permaculture: Caring \& designing for ourselves, each other \& the planet (1st ed.). Permanent Publications.

Macy, J., \& Brown, M. Y. (2014). Coming back to life: The guide to the work that reconnects. New Society Publishers.

Maina-Okori, N. M., Koushik, J. R., \& Wilson, A. (2018). Reimagining intersectionality in environmental and sustainability education: A critical literature review. The Journal of Environmental Education, 49(4), 286-296.

Mäkelä, M. (2007). Knowing through making: The role of the artefact in practice-led research. Knowledge, Technology \& Policy, 20(3), 157-163.

Mang, P., \& Reed, B. (2020). Regenerative development and design. Sustainable Built Environments, 115-141.

Mantere, M. H. (1998). Art and the environment: An art-based approach to environmental education. In L. Rubinstein Reich (Ed.), Rapporter om utbildning (Vol. 3, pp. 30-35). Lärarhögskolan.

Marcuse, H. (1978). The aesthetic dimension. Beacon Press.

Massey, D. (2005). For space. Sage.

Matarasso, F. (2019). A restless art. How participation won, and why it matters. Digital edition. Calouste Gulbenkian Foundation. Viitattu, 15, 2020.

McEwan, C., \& Goodman, M. K. (2010). Place geography and the ethics of care: Introductory remarks on the geographies of ethics, responsibility and care. Ethics, Place and Environment, 13(2), 103-112.

Méndez, M. J. (2018). "The river told me": Rethinking intersectionality from the world of Berta Cáceres. Capitalism Nature Socialism, 29(1), 7-24. 
Molden, D. C. (2014). Understanding priming effects in social psychology: An overview and integration. Social Cognition, 32(Supplement), 243-249.

Moriggi, A., Soini, K., Bock, B. B., \& Roep, D. (2020). Caring in, for, and with nature: An integrative framework to understand green care practices. Sustainability, 12(8), 3361.

Nijland, H. J. (2016). Disentangling the domestic contract: understanding the everyday-life construction of acceptability-or non-acceptability-of keeping and killing animals for food (Doctoral dissertation, Wageningen University).

Noggle, R. (2020). The ethics of manipulation in The Stanford Encyclopedia of Philosophy (Summer 2020 Edition).

Nørgård, R. T., Toft-Nielsen, C., \& Whitton, N. (2017). Playful learning in higher education: Developing a signature pedagogy. International Journal of Play, 6(3), 272-282.

Osborn, A. F. (1953). Applied imagination: Principles and procedures of creative thinking. Charles Scribner's Sons.

Pearson, K. R. (n.d.). Reimaginary. Retrieved April 01, 2021, from https:// www.reimaginary.com/.

Pearson, K. R., Bäckman, M., Grenni, S., Moriggi, A., Pisters, S., \& de Vrieze, A. (2018). Arts-based methods for transformative engagement: A toolkit. SUSPLACE.

Pearson, K. R. (2021, Forthcoming). Imaginative leadership: A conceptual framework for operationalizing creative practices in support of regenerative sustainability. Unpublished Thesis. Wageningen University, The Netherlands.

Pihkala, P. (2020). Eco-anxiety and environmental education. Sustainability, 12(23), 10149.

Rathwell, K., Armitage, D., \& Berkes, F. (2015). Bridging knowledge systems to enhance governance of environmental commons: A typology of settings. International Journal of the Commons, 9(2).

Rathwell, K. J., \& Armitage, D. (2016). Art and artistic processes bridge knowledge systems about social-ecological change: An empirical examination with Inuit artists from Nunavut, Canada. Ecology and Society, 21(2).

Rittel, H. W., \& Webber, M. M. (1973). Dilemmas in a general theory of planning. Policy Sciences, 4(2), 155-169.

Salomaa, A., \& Juhola, S. (2020) How to assess sustainability transformations: A review Global. Sustainability, 3. 
Sannino, A. (2015). The emergence of transformative agency and double stimulation: Activity-based studies in the Vygotskian tradition. Learning, Culture and Social Interaction, (4), 1-3.

Scharmer, C. O. (2009). Theory U: Learning from the future as it emerges. Berrett-Koehler Publishers.

Schein, S. (2017). A new psychology for sustainability leadership: The hidden power of ecological worldviews. Routledge.

Sheridan, K., Halverson, E. R., Litts, B., Brahms, L., Jacobs-Priebe, L., \& Owens, T. (2014). Learning in the making: A comparative case study of three makerspaces. Harvard Educational Review, 84(4), 505-531.

Singer, P. (1981/2011). The expanding circle: Ethics, evolution, and moral progress. Princeton University Press.

Sol, J., Beers, P. J., \& Wals, A. E. J. (2013). Social learning in regional innovation networks: Trust, commitment and reframing as emergent properties of interaction. Journal of Cleaner Production, 49(8), 35-43.

Smith, H. (Ed.) (2009). Practice-led research, research-led practice in the creative arts. Edinburgh University Press.

Stewart, F. (2020). Overcoming short-termism: Incorporating future generations into current decision-making. Irish Studies in International Affairs, $1-17$.

Taylor, C. (2004). Modern social imaginaries. Duke University Press.

Taylor, S. S., \& Ladkin, D. (2009). Understanding arts-based methods in managerial development. Academy of Management Learning \& Education, $8(1), 55-69$.

Thomas, H., Mitchell, G., Rich, J., \& Best, M. (2018). Definition of whole person care in general practice in the English language literature: A systematic review. BMJ Open, 8(12), e023758.

Treffinger, D. J., Isaksen, S. G., \& Dorval, K. B. (1994). Creative problem solving: An overview. Problem Finding, Problem Solving, and Creativity, 223236.

Vadeboncoeur, J. A., \& Vellos, R. E. (2016). Re-creating social futures: The role of the moral imagination in student-teacher relationships in alternative education. International Journal of Child, Youth and Family Studies, 7(2), 307-323.

van Boeckel, J. (2013). At the heart of art and earth: An exploration of practices in arts-based environmental education. Aalto Publications.

van der Vaart, G., van Hoven, B., \& Huigen, P. P. (2019). 'It is not only an artist village, it is much more than that'. The binding and dividing effects of the arts on a community. Community Development Journal, 54(3), 446-462. 
Wahl, D. (2016). Designing regenerative cultures. Triarchy Press.

Wals, A. E. J., \& Heymann, F. V. (2004). Learning on the edge: exploring the change potential of conflict in social learning for sustainable living. In A. Wenden (Ed.), Educating for a culture of social and ecological peace (pp. 123145). SUNY Press. 0-7914-6174-2.

Wang, Q., Coemans, S., Siegesmund, R., \& Hannes, K. (2017). Arts-based methods in socially engaged research practice: A classification framework. Art/research International, 2(2), 5-39.

Warm data lab. (n.d.). Retrieved April 01, 2021, from https://warmdatalab. net/.

Wheatley, M. J. (2017). Who do we choose to be?: Facing reality, claiming leadership, restoring sanity. Berrett-Koehler Publishers.

Wittmayer, J. M., \& Schäpke, N. (2014). Action, research and participation: Roles of researchers in sustainability transitions. Sustainability Science, 9(4), 483-496.

Weintraub, L. (2012). To life!: Eco art in pursuit of a sustainable planet. University of California Press.

Zittoun, T., \& Cerchia, F. (2013). Imagination as expansion of experience. Integrative Psychological and Behavioral Science, 47(3), 305-324.

Open Access This chapter is licensed under the terms of the Creative Commons Attribution 4.0 International License (http://creativecommons.org/ licenses/by/4.0/), which permits use, sharing, adaptation, distribution and reproduction in any medium or format, as long as you give appropriate credit to the original author(s) and the source, provide a link to the Creative Commons license and indicate if changes were made.

The images or other third party material in this chapter are included in the chapter's Creative Commons license, unless indicated otherwise in a credit line to the material. If material is not included in the chapter's Creative Commons license and your intended use is not permitted by statutory regulation or exceeds the permitted use, you will need to obtain permission directly from the copyright holder.

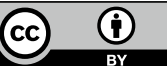

